\title{
Reverse Transcription Inhibition
}

National Cancer Institute

\section{Source}

National Cancer Institute. Reverse Transcription Inhibition. NCI Thesaurus. Code C40691.

Reverse Transcription Inhibition involves interference with, or restraint of, activities involved in copying RNA into DNA by reverse transcriptase. 